\title{
Cross-Reactivity of Peanut Allergens
}

\author{
Merima Bublin • Heimo Breiteneder
}

Published online: 20 February 2014

(C) The Author(s) 2014. This article is published with open access at Springerlink.com

\begin{abstract}
Peanut seeds are currently widely used as source of human food ingredients in the United States of America and in European countries due to their high quality protein and oil content. This article describes the classification and molecular biology of peanut seed allergens with particular reference to their cross-reactivities. Currently, the IUIS allergen nomenclature subcommittee accepts 12 peanut allergens. Two allergens belong to the cupin and four to the prolamin superfamily, and six are distributed among profilins, Bet v 1-like proteins, oleosins, and defensins. Clinical observations frequently report an association of peanut allergy with allergies to legumes, tree nuts, seeds, fruits and pollen. Molecular cross-reactivity has been described between members of the Bet $\mathrm{v}$ 1-like proteins, the non-specific lipid transfer proteins, and the profilins. This review also addresses the less well-studied cross-reactivity between cupin and prolamin allergens of peanuts and of other plant food sources and the recently discovered cross-reactivity between peanut allergens of unrelated protein families.
\end{abstract}

Keywords 2S albumin · Allergy · Allergen · Arah $1 \cdot$ Arah 2 . Ara h $3 \cdot$ Ara h $8 \cdot$ Ara h $9 \cdot$ Bet v 1 - Cross-reactivity · Cupin . Food allergy $\cdot$ Food allergen $\cdot$ Immunoglobulin E $\cdot$ Lentil allergy $\cdot$ Lupin allergy $\cdot$ NSLTP $\cdot$ Oleosins $\cdot$ Protein family Peanut $\cdot$ Peanut allergen · Profilin · Prolamin · Soy allergy · Tree nut allergy

\section{Introduction}

Peanuts are the seeds of the peanut plant (Arachis hypogaea) which is a member of the legume family (Fabaceae). The

This article is part of the Topical Collection on Allergens

M. Bublin $\cdot$ H. Breiteneder $(\bowtie)$

Department of Pathophysiology and Allergy Research, Medical University of Vienna, Währinger Gürtel 18-20, 1090 Vienna, Austria

e-mail: heimo.breiteneder@meduniwien.ac.at peanut is botanically related to beans and peas but not to tree nuts. The typical peanut seed pod which usually contains two seeds matures buried underground. Peanuts are very rich in nutrients and are one of the basic crops of India, China, the USA and West Africa. Peanuts contain 44-56 \% oil and 22 $30 \%$ protein [1]. The total protein content of three of the most commonly used peanut cultivars (Valencia, Virginia, and Spanish) was determined to be between 24 and $29 \%$ [2]. Most of the protein content is made up by seed storage proteins of the cupin or prolamin superfamilies. The cupin Ara h 1 was determined to contribute $12-16 \%$, and the $2 \mathrm{~S}$ albumin Ara h $25.9-9.3 \%$ to the total protein content of a peanut [2]. In a recent study, all known peanut allergen classes were determined to comprise $85 \%$ of the total protein content of peanut while Ara h 1, Ara h 2, and Ara h 3 together accounted for $75 \%$ [3].

\section{Foundation of Cross-Reactivity}

Cross-reactivity relies on the presence of conserved antibodyaccessible surface structures of proteins and is hence observed in general between members of the same protein family. Protein evolution is linked to the evolution of species. Thus proteins that appeared very early in the evolutionary process are distributed much wider than proteins that appeared later on. The cupin and the Bet $\mathrm{v} 1$ architectures can be traced back to the Archaea. Archaea are also the oldest form of life on earth with an estimated age of 3.5 billion years $[4,5]$. The typical cupin domain first appeared in extremophile Archaea [6]. The most important storage proteins of legumes, tree nuts and seeds are members of the cupin superfamily [7]. Aeropyrum pernix, an archaeon that was isolated from a hydrothermal vent near a Japanese island in 1996 [8], produces the protein APE2225 (PDB accession no. 2NS9) whose architecture is identical to that of Bet $\mathrm{v} 1$ (PDB 1BV1). Like members of the cupin superfamily, Bet $\mathrm{v}$ 1-like proteins can be found in all three domains of life including birch pollen and peanut [9]. In 
contrast, the prolamin superfamily seems to be of a later origin. Non-specific lipid transfer proteins (nsLTPs) have only been identified in seed plants but are not even present in algae [10•]. Thus, protein evolution explains the occurrence of so-called panallergens - such as the Bet $\mathrm{v} 1$ homologs - in many unrelated allergen sources. However, the in vitro-observed IgE cross-reactivity of such panallergens is not always associated with clinical symptoms. Only recently, cross-reactivity between two unrelated protein architectures has been described for the first time. The cross-reactivity between the $2 \mathrm{~S}$ albumin Ara h 2 and the cupins Ara h 1 and 3 is based on the presence of short similar structural motifs [11•].

\section{Clinical Relevance of Cross-Reactivity}

Twelve allergens of peanut have been included in the official allergen nomenclature database (http://www.allergen.org/) to date. They belong to the cupin (Ara h 1, Ara h 3), the prolamin (Ara h 2, Ara h 6, Ara h 7, Ara h 9), the profilin (Ara h 5), the Bet v 1 (Ara h 8), the glycosyl transferase GT-C (Ara h 10, Ara $\mathrm{h} 11$ ), and the scorpion toxin-like knottin (Ara h 12, Ara h 13) superfamilies (Figs. 1 and 2).

Ara $\mathrm{h} 8$, a homolog of the major birch pollen allergen Bet $\mathrm{v}$ 1 , and Ara h 5, a profilin, are mostly involved in pollenassociated food allergy, while the peanut nsLTP Ara $\mathrm{h} 9$ is involved in the so-called nsLTP-syndrome due to the crossreactivity with their homologs in birch and/or grass pollen or in fruits and seeds, respectively. Ara h 2 was described as the most important peanut allergen, as it was identified as a predictor of clinical reactivity to peanut [12-14]. On the other hand, monosensitization to a single peanut allergen is relatively rare [15], and patients with monosensitization to Ara h 2 had a significantly lower symptoms severity score than polysensitized subjects and a lower level of allergen-specific IgE against peanut extract and Ara $h 2$ [16]. Polysensitization to Ara h 2 and Ara h 1 and/or Ara h 3 appeared to be predictive of more severe reactions [16-19].

In peanut-allergic patients a clinically relevant sensitization to other legumes such as soybean, lupin, lentil, or pea occurs; however, little information is available. In a group of 39 peanut-sensitized patients, 82,55 , and $87 \%$ of patients were also sensitized to lupine, pea, and soybean, respectively, whereas, based on DBPCFC, 29-35\% had symptoms to these beans [20]. In a recent study, Klemens and colleagues showed that $60 \%$ of soy-allergic patients had a concomitant peanut allergy and significantly more often specific IgE to soy extract, the soy $2 \mathrm{~S}$ albumin Gly $\mathrm{m} 8$ and the soy cupins Gly $\mathrm{m} 5$ and Gly $\mathrm{m} 6$ compared to the peanut-tolerant group [21•].

Between 20 and $40 \%$ of peanut-allergic individuals have a co-existing allergy to taxonomically distantly related tree nuts $[22,23]$. In a large study including 324 peanut-allergic patients, $86 \%$ were sensitized to tree nuts, and $34 \%$ had clinical documented allergy [24]. The numbers may even be higher than those reported in a study by Glaspole and colleagues where up to $60 \%$ of peanut-allergic individuals examined in their adult allergy clinic were allergic to one or more tree nuts with the most common reactivity of $49 \%$ to hazelnuts [25].

In the majority of the cases, the identity of the crossreactive allergens was not investigated.

Using nut protein extracts and sera from subjects with peanut and tree nut allergy in inhibition ELISA, de Leon and colleagues demonstrated serum IgE cross-reactivity between allergens present in peanut, almond, Brazil nut and hazelnut [26]. No IgE cross-reactivity between peanut and cashew was detected. In a next step, de Leon and co-workers purified peanut-specific IgE from sera of two peanut-allergic individuals [27]. They then isolated basophils from atopic but nonpeanut-allergic subjects, stripped the cells of bound $\operatorname{IgE}$ and resensitized them with purified peanut-specific IgE. The basophils were activated by extracts from peanut, almond, Brazil nut, and hazelnut but to a lesser degree by cashew.

In vivo cross-reactivity between cashew, walnut and peanut was assessed in $\mathrm{C} 3 \mathrm{H} / \mathrm{HeJ}$ mice [28]. Mice were sensitized by intraperitoneal injection of protein extracts from cashew alone or from cashew and walnut. Mice sensitized to only cashew reacted almost as strongly to walnut as they did to cashew, with the vicilin-like Jug $\mathrm{r} 2$ being implicated as the crossreactive allergen. Only mild symptoms were observed when challenging these mice with peanut. Mice sensitized to cashew and walnut had higher anaphylactic scores when challenged with the tree nuts but still produced weaker reactions to peanut. Both groups of mice showed strong T cell proliferative responses to cashew and walnut and weaker responses to peanut.

\section{Allergenic Peanut Cupins}

A proteomic study by Chassaigne and colleagues revealed the presence of two Ara h 1 and six Ara h 3 isoforms in protein extracts of the peanut variety Virginia [29]. In this study, Ara $h$ 1 was resolved into ten and Ara h 3 into eight protein spots illustrating the complexity of the peanut allergome. Although the number of proteins in the peanut seed proteome is relatively low, the presence of the numerous isoforms for each protein family member complicates the proteomic investigation [3]. Furthermore, Ara h 1 and Ara h 3 are incorporated into high molecular weight protein complexes upon roasting [30].

\section{Ara h 1}

The cupin allergen Ara h 1 has been identified as member of the vicilin seed storage family [31]. The vicilins or 7S globulins are typically disk-shaped trimeric proteins whose subunit compositions vary considerably due to the extent of posttranslational proteolytic processing and glycosylation [32]. 


\begin{tabular}{|c|c|c|c|c|c|c|}
\hline \multirow{3}{*}{$\begin{array}{l}\text { Protein } \\
\text { superfam ily } \\
\text { Protein family }\end{array}$} & \multicolumn{2}{|c|}{ Cupin } & \multicolumn{4}{|c|}{ Prolamin } \\
\hline & Vicilin or $7 \mathrm{~S}$ globulin & Legumin or $11 \mathrm{~S}$ globulin & \multicolumn{3}{|c|}{$2 \mathrm{~S}$ albumin } & \multirow{2}{*}{$\begin{array}{l}\text { nsLTP } \\
\text { Ara h } 9\end{array}$} \\
\hline & Ara h 1 & Ara h 3 & Ara h 2 & Ara h 6 & Ara h 7 & \\
\hline $\begin{array}{l}\text { Isoallergen } \\
\text { (UniProt) }\end{array}$ & Ara h 1.0101 (P43238) & $\begin{array}{l}\text { Ara h } 3.0101(\mathrm{O} 82580) \\
\text { Ara h } 3.0201 \text { (Q9SQH7) }\end{array}$ & $\begin{array}{l}\text { Ara h 2.0101 } \\
\text { (Q6PSU2) } \\
\text { Ara h 2.0201 } \\
\text { (Q6PSU2) }\end{array}$ & $\begin{array}{l}\text { Ara h 6.0101 } \\
\text { (Q647G9) }\end{array}$ & $\begin{array}{l}\text { Ara h 7.0101 } \\
\text { (Q9SQH1) } \\
\text { Ara h 7.0201 } \\
\text { (B4XID4) }\end{array}$ & $\begin{array}{l}\text { Ara h } 9.0101 \text { (B6CEX8) } \\
\text { Ara h } 9.0201 \text { (B6CG41) }\end{array}$ \\
\hline $\begin{array}{l}\text { Molecular mass } \\
\text { (kDa) and } \\
\text { theoretical pl }\end{array}$ & $\begin{array}{l}\text { monomer } 63.5 \mathrm{kDa} ; \mathrm{pI} 4.6 \\
\text { occurs as trimer of } 180 \mathrm{kDa}\end{array}$ & $\begin{array}{l}\text { monomer } 60.0 \mathrm{kDa} \text {; pI } 4.6 \\
\text { occurs as hexamer of } 360 \mathrm{kDa}\end{array}$ & $\begin{array}{l}16.6 \mathrm{kDa} ; \mathrm{pI} 5.8 \\
18.0 \mathrm{kDa} ; \mathrm{pI} 5.5\end{array}$ & $\begin{array}{l}15.0 \mathrm{kDa} ; \mathrm{pI} \\
5.5\end{array}$ & $\begin{array}{l}16.4 \mathrm{kDa} ; \mathrm{pI} 5.6 \\
17.4 \mathrm{kDa} ; \mathrm{pI} 7.5\end{array}$ & $\begin{array}{l}9.1 \mathrm{kDa} ; \mathrm{pI} 9.5 \\
9.1 \mathrm{kDa} \text {; } \mathrm{I} 9.3\end{array}$ \\
\hline \multirow[t]{2}{*}{$\begin{array}{l}\text { Representative } \\
\text { protein structure }\end{array}$} & & & & 580 & & \\
\hline & Ara h 1PDB: 3S7E [34] & Ara h 3 PDB: $3 \mathrm{C} 3 \mathrm{~V}$ [47] & \multicolumn{3}{|c|}{ Ara h 6 PDB: 1W2Q [63] } & $\begin{array}{l}\text { Pru p } 3 \text { PDB: } 2 \mathrm{ALG} \\
{[115]}\end{array}$ \\
\hline $\begin{array}{l}\text { Biological } \\
\text { function }\end{array}$ & \multicolumn{2}{|c|}{ provide nourishment for the growth of the seedlings } & \multicolumn{3}{|c|}{$\begin{array}{l}\text { sources of amino acids for growth of seedlings; } \\
\text { involved in defense against pathogens }\end{array}$} & $\begin{array}{l}\text { involved in defense } \\
\text { agains pathogens and in } \\
\text { the formation of hydro- } \\
\text { phobic layers in plant }\end{array}$ \\
\hline $\begin{array}{l}\text { Prevalence of } \\
\text { IgE binding }\end{array}$ & $30-80 \%[17,83]$ & $16-57 \%[17,83]$ & $42-100 \%[116,83]$ & $\begin{array}{l}86-92 \%[79, \\
116]\end{array}$ & $43 \%[79]$ & $\begin{array}{l}8-60 \%, \text { strong } \\
\text { association with peach } \\
\text { allergy }[84,83]\end{array}$ \\
\hline Cross-reactivity & $\begin{array}{l}\text { with other legume and tree nut } \\
\text { vicilins and Ara h } 2 \text { and Ara h } 3 \\
{[43,11]}\end{array}$ & $\begin{array}{l}\text { with other legumes and tree nut } \\
\text { legumins and Ara h 1,2, and } 6[43 \text {, } \\
\text { 11] }\end{array}$ & $\begin{array}{l}\text { with } 2 \mathrm{~S} \text { albumins } \\
\text { from almond and } \\
\text { Brazil nut, and Ara } \mathrm{h} \\
1,3 \text {, and } 6[11,26]\end{array}$ & $\begin{array}{l}\text { with Ara h } 1 \text {, } \\
2,3[11]\end{array}$ & not known & $\begin{array}{l}\text { with peach and hazelnut } \\
\text { nsLTPs (Pru p } 3 \text { and Cor } \\
\text { a 8) [84] }\end{array}$ \\
\hline
\end{tabular}

Fig. 1 Allergenic cupins and prolamins from peanut

They lack cysteine residues and hence cannot form disulfide bonds. The crystal structure of Ara $\mathrm{h} 1$ has been elucidated and can be accessed under the PDB (protein database, http://www. rcsb.org/) numbers 3SMH [33] and 3S7I [34•] (Fig. 1).
Besides Ara $\mathrm{h}$ 1, a range of allergenic vicilins has been described, including those from soybean (Gly m 5) [35], pea (Pis s 1) [36], cashew nut (Ana o 1) [37], walnut (Jug r 2) [38], lentil (Len c 1) [39], sesame (Ses i 3) [40], and hazelnut (Cor a

\begin{tabular}{|c|c|c|c|c|}
\hline Protein & Bet v 1-like & Profilin & Glycosyl transferase GT-C & \multirow[t]{2}{*}{ Scorpion toxin-like knottin } \\
\hline Protein family & Bet v 1 family & Profilin & Oleosins & \\
\hline Allergen & Ara h 8 & Ara h 5 & Ara h 10 & Ara h 13 \\
\hline $\begin{array}{l}\text { Isoallergen } \\
\text { (UniProt or } \\
\text { GenBank No.) }\end{array}$ & $\begin{array}{l}\text { Ara h } 8.0101 \text { (Q6VT83) } \\
\text { Ara h } 8.0201 \text { (B0YIU5) }\end{array}$ & Ara h 5.0101 (Q9SQ19) & $\begin{array}{l}\text { Ara h } 10.0101 \\
\text { (Q647G5) } \\
\text { Ara h 10.0201 } \\
\text { (Q647G4) }\end{array}$ & $\begin{array}{l}\text { Ara h } 12.0101 \\
(\mathrm{EY} 396089)\end{array}$ \\
\hline $\begin{array}{l}\text { Molecular mass } \\
\text { (kDa) and } \\
\text { theoretical pI }\end{array}$ & $17.0 \mathrm{kDa} ; \mathrm{pI} 5.0$ & $14.0 \mathrm{kDa} ; \mathrm{pI} 4.6$ & $14.3 \mathrm{kDa} ; \mathrm{pI} 10.1$ & $5.2 \mathrm{kDa} ; \mathrm{pI} 7.7$ \\
\hline $\begin{array}{l}\text { Representative } \\
\text { protein } \\
\text { structure }\end{array}$ & con & 420 & no oleosin structure available & \\
\hline & Ara h 8 PDB: 4M9B [92] & Ara h 5 PDB: 4ESP [87] & & $\begin{array}{l}\text { defensin from germinated lentil seeds } \\
\text { PDB: 2LJ7 [117] }\end{array}$ \\
\hline $\begin{array}{l}\text { Biological } \\
\text { function }\end{array}$ & $\begin{array}{l}\text { might serve as a delivery } \\
\text { vehicle for flavonoids }\end{array}$ & $\begin{array}{l}\text { regulate polymerization and } \\
\text { depolymerization of actin } \\
\text { monomers }\end{array}$ & structural proteins of oil bodies in seeds & $\begin{array}{l}\text { antifungal, antibacterial, protease inhibitory } \\
\text { or insect amylase inhibitory activity in } \\
\text { plants }\end{array}$ \\
\hline $\begin{array}{l}\text { Prevalence of } \\
\text { IgE binding }\end{array}$ & $\begin{array}{l}\text { relevant for birch pollen } \\
\text { allergic patients, ca. } 22- \\
66 \%[17,83]\end{array}$ & $\begin{array}{l}3-24 \% \text { of birch or grass } \\
\text { pollen allergic patients }[83]\end{array}$ & not known & not known \\
\hline Cross-reactivity & $\begin{array}{l}\text { with Bet } v 1 \text { and other } \\
\text { PR-10 proteins, e.g. from } \\
\text { soy or lentil }[89,88]\end{array}$ & $\begin{array}{l}\text { with other profilins e.g. Bet v } \\
2 \text { and } \mathrm{Phl} \text { p } 12 \text { [85] }\end{array}$ & with ole osins from soy and buckwheat $[99,95]$ & not known \\
\hline
\end{tabular}

Fig. 2 Peanut allergens from the Bet v 1, profilin, oleosin, and defensin families 
11) [41]. A crystal structure for the Ara h 1-related allergen Gly $\mathrm{m} 5$ homotrimer is available [42]. Barre and colleagues built models of vicilin-like allergens from peanut (Ara h 1), walnut (Jug r 2), hazelnut (Cor a 11), and cashew nut (Ana o 1) using the $\mathrm{x}$-ray coordinates of soybean Gly $\mathrm{m} 5$ to illustrate the structural similarity of these allergens [43]. In addition, their molecular modeling study included one experiment with a pool of an undisclosed number of sera from peanut-allergic patients, which indicated $\operatorname{IgE}$ reactivity to the tree nut allergens Ana o 1, Cor a 11, and Jug r 2, as well as to the soybean allergen, Gly m 5.

The question of allergenic potential of cross-reactive $7 \mathrm{~S}$ globulins and thus of the origin of sensitization was addressed in an interesting recent study using Brown Norway (BN) rats [44•]. BN rats were sensitized i.p. without the use of an adjuvant with purified 7S globulins from peanut (Ara h 1), hazelnut (Cor a 11), pea (Pis s 1), and soy (Gly m 5). Although the four related $7 \mathrm{~S}$ globulins induced very similar IgG and IgE titers, Ara $\mathrm{h} 1$ induced IgE of higher avidity than Cor a 11 and Pis s 1, which had higher avidity than Gly $\mathrm{m}$ 5. Glaspole and colleagues reported that hazelnut-specific $T$ cell lines obtained from patients with co-allergy to hazelnut and peanut proliferated upon stimulation with Ara h 1 or Ara h 2 and expressed both IL-5 and INF- $\gamma$ [25]. Shared T cell epitopes between hazelnut and peanut proteins may contribute to the observed co-sensitization that was previously also observed on the $\operatorname{IgE}$ level [26].

A recent study used peptide arrays to examine IgE-binding to sequential B cell epitopes of Ara $\mathrm{h} 1$ and the related walnut allergen Jug $\mathrm{r} 2$ from sera of 32 peanut-allergic patients with or without clinically relevant walnut allergy [45]. Interestingly, no differences in the recognition of these peptides were observed between the two groups of patients nor could any relevant cross-reactive IgE antibodies be detected in inhibition assays. The authors concluded that the sequence stretches previously identified as sequential IgE-binding epitopes of Ara h 1, Ara h 2, and Ara h 3 had no equivalents in walnut allergens.

\section{Ara h 3}

Ara $\mathrm{h} 3$ is a cupin allergen identified in peanut that belongs to the legumin family [46]. The allergen nomenclature subcommittee has renamed Ara h 4.01 to Ara h 3.02 as its sequence shares $91 \%$ identity with that of Ara $\mathrm{h} 3$, by far exceeding the $67 \%$ identity threshold for naming isoallergens [7]. Legumins or $11 \mathrm{~S}$ globulins are hexameric proteins that are found in the seeds of many plants. Their subunits are synthesized as a single polypeptide which is then cleaved to give rise to an acidic and a basic polypeptide chain that are linked by a single disulfide bond [32]. Legumins are not usually glycosylated. The crystal structure of Ara h 3 was determined and can be accessed under the PDB number 3C3V [47] (Fig. 1).
Additional allergenic legumins have been described in legumes, tree nuts and seeds including those from soybean (Gly m 6) [48], cashew nut (Ana o 2) [49], walnut (Jug r 4) [50], sesame (Ses i 7) [51], and hazelnut (Cor a 9) [52]. Crystal structures for Ara $\mathrm{h} 3$-related allergens are available for Gly $\mathrm{m}$ $6.0101[53]$ and Gly m $6.0501[54,55]$ from soybean and for Pru du 6 from almond [56].

Barre and coworkers mapped linear IgE epitopes identified in Ara h 3, Jug r 4, Cor a 9, and Ana o 2 on three-dimensional models of these allergens built by homology modeling using the Gly $\mathrm{m} 6$ structure 1OD5 from Adachi as a template [57]. The authors' analyses revealed that these surface-exposed IgE epitopes exhibited some structural similarities, thus accounting for the observed IgE cross-reactivity between peanut and tree nut allergens. The legumin-like Sin a 2 has been identified as a diagnostic marker to indicate a risk for severe symptoms triggered by mustard consumption [58•]. Inhibition experiments using sera from mustard-allergic and Sin a 2-positive patients revealed IgE cross-reactivity between Sin a 1 and $11 \mathrm{~S}$ globulins from peanut and tree nuts [59].

\section{Allergenic Peanut Prolamins}

The prolamin superfamily contains the largest number of allergenic plant proteins [60]. It comprises several related protein families that contain a characteristic well-conserved pattern of eight cysteine residues but have low or almost no sequence identity. Despite the diversity of their function and low overall sequence identity between the conserved regions, these proteins all share a similar 3-dimensional structure consisting of bundles of four alpha-helices stabilized by disulfide bonds [61]. Members of the prolamin superfamily identified in peanut as allergens include $2 \mathrm{~S}$ albumins and a type 1 non-specific lipid binding protein (nsLTP). Three peanut allergens belong to the $2 \mathrm{~S}$ albumin family: Ara h 2, Ara h 6, and Ara h 7. As Ara h 2 shows $59 \%$ amino acid sequence identity to Ara h 6 and $42 \%$ to Ara h 7, they are designated as three different allergens in accordance to recommendations of WHO/IUIS Allergen Nomenclature Subcommittee. The peanut allergen Ara $\mathrm{h} 9$ is a member of the nsLTP family which is widely distributed among plants.

\section{The 2 S Albumins Ara h 2 and Ara h 6}

The majority of $2 \mathrm{~S}$ albumins are synthesized as proproteins which are then proteolytically processed in the vacuole into two subunits with four disulfide bonds. In contrast, peanut $2 \mathrm{~S}$ albumins are not post-translationally modified except for the formation of disulfide bonds. As a result, the proteins occur in peanut as single polypeptide chains. Only the so-called asparagine-containing form of Ara $\mathrm{h} 6$ has been found to be processed into a large $(9.2 \mathrm{kDa})$ and a small subunit $(5.4 \mathrm{kDa})$ 
linked via two disulfide bonds [62]. The structures of Ara h 2 (PDB: 3OB4) and Ara h 6 (PDB: 1W2Q) resemble that of other 2S albumins such as Ric c 3 (PDB: 1PSY) from castor bean, SFA-8 (PDB: 1S6D) from sunflower or Ber e 1 (PDB: 2LVF) from Brazil nut showing a common fold of antiparallel bundles of four helices held together by disulfide bonds in a right-handed superhelix fold (Fig. 1). A non-structured loop of Ara h 2 connecting alpha-helices 3 and 4, known also as a hypervariable loop, is almost doubled in size compared to Ara h 6 . In addition, compared to Ara h 2, Ara h 6 contains a fifth disulfide bond linking the C-terminus to the compact fold, which in Ara h 2 is flexible and without regular secondarystructure elements $[63,64]$.

Ara h 2 has found the highest attention as it is regarded as the most potent peanut allergen. There are two isoforms of Ara h 2, designated as Ara h 2.0101 and Ara h 2.0201, with molecular masses of 16.7 and $18 \mathrm{kDa}$, respectively [65, 66]. Ara $\mathrm{h} 2.0201$ contains an insertion of 12 amino acids in the hypervariable region containing the immunodominant $\operatorname{IgE}$ epitope [67]. The molecular masses of the two isoforms determined by mass spectrometric analysis correspond to the molecular weights calculated from the encoding genes [68], suggesting that Ara h 2 is not glycosylated as previously reported [65]. Among ten identified linear IgE-binding epitopes, three were immunodominant and located in the exposed and structurally flexible regions in the folded protein [69]. These three IgE-binding epitopes have been recently defined as the peptide biomarkers for prediction of symptomatic peanut allergy [12] and have been found to be particularly responsible for the cross-reactivity between Ara h 2 and Ara h 1, Ara h 3, and Ara h 6 [11•]. The conformational structure of Ara h 2 and Ara h 6 plays a critical role in allergenicity. Disruption of disulfide bonds by complete reduction and Salkylation of these allergens drastically alters their IgEbinding capacity and effector cell activity [70, 71]. Dreskin and colleagues have found that Ara h 2 and Ara h 6 together account for the majority of the effector activity of whole peanut extract $[72,73]$, and demonstrated that Ara $\mathrm{h} 2$ and Ara $\mathrm{h} 6$ are not only major elicitors of anaphylaxis but can also effectively desensitize peanut-allergic mice [74•].

Although, co-sensitization to peanut and tree nuts is common, and many $2 \mathrm{~S}$ albumins are known as important allergens in tree nuts such as Jug r 1 from walnut, Ber e 1 from Brazil nut, Cor a 14 from hazelnut, and Car i 1 from pecan, there are almost no experimental data about cross-reactivity between Ara h 2 and these allergens. Only one study using three sera from peanut-allergic patients showed that rAra h 2 shares IgEbinding epitopes with almond and Brazil nut, but not with cashew and hazelnut allergens [75]. Maleki and colleagues examined the IgE cross-reactivity between walnut and peanut allergens by testing sera of walnut- and peanut-allergic sera for IgE-binding to peptides representing predicted walnut and known and predicted peanut allergen epitopes [76].
Interestingly, a predicted Jug r 2 epitope not only bound IgE from the sera but also inhibited IgE-binding to the $2 \mathrm{~S}$ albumin allergen Ara h 2. Jug r 2 and Ara h 2 belong to two different protein families and share only about $13 \%$ sequence identity.

\section{The 2S Albumin Ara h 7}

Initially, Ara h 7 was identified as an IgE-binding protein by phage display technology. In contrast to the conserved cysteine skeleton of $2 \mathrm{~S}$ albumins with at least eight cysteines, Ara $\mathrm{h}$ 7.0101 had only six and missed two such residues in its Cterminus [77]. Schmidt and colleagues cloned a new isoform, Ara $\mathrm{h}$ 7.0201, with the typical $2 \mathrm{~S}$ albumin cysteine signature, and they found that the determined amino acid sequence of Ara $\mathrm{h} 7.0101$ was the consequence of a nucleotide insertion that resulted in a shift of the reading frame and the generation of a different C-terminus [78]. Accordingly, only Ara h 7.0201 was identified at the protein level in peanut protein extracts. It is a $17.3-\mathrm{kDa}$ protein with a pI of 7.7 and makes up only $0.5 \%$ of total peanut protein extract. Ara h 7.0201 shows $42 \%$ amino acid sequence identity to Ara h 2.0201 and $43 \%$ to Ara $\mathrm{h} 6$, the highest diversity being found in the hypervariable region. Sera of around $43 \%$ of 40 peanut-allergic patients contained IgE specific for Ara h 7.0101, but no study on the prevalence or allergenic properties has been performed for Ara h 7.0201 which is the Ara h 7 isoform that is actually present in peanut [79].

\section{The nsLTP Ara h 9}

The nsLTPs share a common architecture that is characterized by the presence of a hydrophobic cavity enclosed by four or five alpha helices and stabilized by four conserved disulfide bridges [61]. Sequence identities between nsLTPs from different plants tend to be low even though their 3-dimensional structures are very similar. Although their ability to transfer various lipid molecules between lipid bilayers in vitro has been well reported, the biological function of nsLTPs in vivo is still unclear. Their involvement in plant defense against pathogens and in the formation of protective hydrophobic layers on the surface of some plant organs has been suggested (reviewed in [10•, 80]).

Ara h 9 is a typical nsLTP with a molecular mass of $9.1 \mathrm{kDa}$ and a basic pI of 9.2-9.4. Two isoforms of Ara $h 9$ with a sequence identity of $90 \%$ were designated as Ara h 9.0101 and Ara h 9.0201. Many studies have reported the importance of Ara h 9 in peanut-allergic patients, mainly in the Mediterranean area but also in some nsLTP-sensitized patients from Central Europe [81, 82, 83•]. Recently, a report was published about the strong association between peach, peanut, and hazelnut allergy in a Spanish peanut-allergic patients group [84]. Ninety percent of 42 peanut-allergic patients were sensitized to Pru p 3, $82 \%$ to Ara h 9, and $74 \%$ to the hazelnut nsLTP 
Cor a 8. Most of the patients reported that symptoms to peanut and later on to hazelnut appeared after they had become allergic to peach. Pru p 3 showed a strong capacity to inhibit IgE-binding to Ara h 9 and Cor a 8, while Ara h 9 and Cor a 8 were unable to inhibit IgE-binding to Pru p 3. Altogether, these findings suggested that the peach allergen Pru p 3 in these patients acted as the primary sensitizer [84].

\section{The Peanut Profilin Ara h 5}

The peanut profilin, Ara h 5, is a minor peanut allergen which is involved in pollen-associated peanut allergy. Different profiles of profilin sensitization in peanut-allergic patients have been described in different areas of the world, with a sensitization rate of $3.3 \%$ in the United States, $9-16 \%$ in Northern and Central Europe, and $24 \%$ in Spanish peanut-allergic patients $[17,83 \bullet, 85,86]$. This is in line with the assumption that, in accordance with the prevalence of sensitization to birch and grass pollen in Northern, Central and Southern Europe, primary sensitization to profilin is caused by birch pollen profilin Bet v 2 and/or grass pollen profilin $\mathrm{Phl} \mathrm{p} \mathrm{12.} \mathrm{This} \mathrm{is} \mathrm{also} \mathrm{supported} \mathrm{by}$ the study of Cabanos and colleagues where $\operatorname{IgE}$ reactivity to Ara h 5 coincided with that of two other profilins, Phl p 12 and Bet v 2, confirming cross-reactivity [85]. They also found potential surface-exposed sequential and discontinuous epitopes of Ara h 5, comprising highly conserved and variable regions, features that may contribute to the cross-reactivity as well as species-specific IgE-reactivity. The presence of the putative specific epitopes might explain the relatively higher IgE-reactivity of the three peanut-allergic patients to Ara $\mathrm{h} 5$ as compared to Phl p 12 and Bet v 2.

Wang and colleagues have recently solved the structure of Ara h 5 (PDB:4ESP) and demonstrated that the overall fold of the protein, similar to previously described profilins, had a central seven-stranded antiparallel $\beta$-sheet with two $\alpha$-helices at the amino-terminal side on one side and one helix at the carboxy-terminal side [87] (Fig. 2). Structure alignments revealed that Ara h 5 is more similar to Bet v 2 than to Hev b 8, although sequence alignments suggested that Ara $\mathrm{h} 5$ is more closely related to Hev b 8 than to Bet v 2 .

\section{The Bet v 1-Like Ara h 8}

Bet v 1 from birch pollen often induces cross-reactive IgE that reacts with related allergens in certain fruits, vegetables, tree nuts and legumes including peanut. Peanuts contain an allergenic member of the family 10 of pathogenesis-related proteins, the Bet v 1-related allergen Ara h 8. Mittag and colleagues cloned its cDNA, expressed and characterized the recombinant protein [88]. Of the 20 peanut- and birch pollen-allergic individuals included in this study, 17 had IgE specific for rAra h 8 .
In 12 of these 17 patients, the anti-peanut response was dominated by Ara $\mathrm{h} 8$. IgE binding to $\mathrm{A}$ Ara $\mathrm{h} 8$ was inhibited by Bet $\mathrm{v} 1$ in peanut extract immunoblotting and in RAST inhibition. On DBPCFC, two of three Ara h 8-monosensitized patients experienced systemic reactions whereas one patient had only OAS. These data showed that a clinically relevant crosssensitization, and the risk to develop serious allergic reactions existed in individuals with concurrent birch pollen and peanut allergy. Potential cross-reactivity between Ara h 8, Bet v 1 and a PR-10 protein from white lupin was shown by an in silico approach [89]. Cross-reactivities between rBet v 1, rAra h 8 and rGly $\mathrm{m} 4$, the homolog from soybean, were later confirmed by performing IgE inhibition studies with sera of birch pollenallergic patients who also had food allergy to peanut and soy [90]. In the same study, one IgE-binding surface area present on all three molecules was identified by using phage-displayed epitope mimics and computer-based mapping of the selected peptide mimics. Riecken and colleagues developed a purification strategy for natural Ara $\mathrm{h} 8$ from peanuts and could show that the purified protein, designated as Ara h 8.0201, differed significantly from the previously published Ara $\mathrm{h} 8.0101$ isoform whose sequence they could only identify on the genomic DNA but not the mRNA level [91]. The authors emphasize that the natural counterpart to a recombinant allergen represents an excellent and necessary reference point. Very recently, the structure of the Ara h 8.0101 isoform was determined from a recombinant protein expressed in E. coli [92•] (Fig. 2). The authors surveyed an array of potential physiologically relevant ligands and identified the phytoestrogen flavonoids quercetin, apigenin, and daidzein as avidly binding in the hydrophobic cavity of Ara h 8.0101, suggesting that Ara h 8 might serve as a delivery vehicle for flavonoids. Quercetin-3-O-sophoroside was identified as the natural ligand of Bet v 1 [93]. The IgE reactivity and the proteolytic stability of nAra $\mathrm{h} 8$ was shown to be increased after roasting possibly due to the association of the allergen with lipophilic ligands and/or the formation of neoepitopes [94].

\section{The Peanut Oleosins Ara h 10 and Ara h 11}

Peanut oleosins have also been implicated in peanut hypersensitivity [95]. In oil seeds, oleosins are structural proteins of intracellular lipid storage organelles called oil bodies. Oil bodies include a matrix of triacylglycerols (oil) enclosed by a layer of phospholipids embedded with oleosins. Oleosins are restricted to plants and are very abundant in seeds, e.g., peanuts, due to their high oil contents (44-56\% [1]), but they are also found in the tapetum cells of anthers in Arabidopsis and Brassica. An oleosin molecule can be divided into the Nand C-terminal hydrophilic portions on the surface of the oil bodies and a central hydrophobic domain that contains the unique proline knot that is anchored into the oil bodies. 
Interestingly, the central hydrophobic stretch of 72 uninterrupted non-polar residues which penetrates the surface phospholipid monolayer is twice as long as any found in all prokaryotic and eukaryotic proteins (for reviews, see [96, 97]). Recently, it has been shown that oleosins, beside their structural function, may also assist in the biosynthesis and mobilization of oils. The oleosin 3 (OLE3; UniProt: Q647G4) of immature peanut seeds has been shown to have both a monoacylglycerol acyltransferase and phospholipase A2 activity suggesting involvement in accumulation of oil and phospholipid hydrolysis [98].

Although the first formal evidence of an $18 \mathrm{kDa}$ oleosin involvement in allergy was reported more than 10 years ago, data about in vitro and in vivo relevance of oleosins for peanut-allergic patients are very scarce. Up to now, five different IgE-binding peanut oleosins with a molecular weight from $14-18 \mathrm{kDa}$ and alkaline $\mathrm{pI}$ from $8.9-9.6$ have been identified $[95,99,100]$. Two of them are included in the official list of allergens. A 14-kDa peanut oleosin was designated as Ara h 11 (UniProt No. Q84T21) and the two isoforms with a molecular weight of 17.8 and $15.5 \mathrm{kDa}$ and a sequence identity of $87 \%$ were designed as Ara h 10.0101 (UniProt No. Q647G5) and Ara h 10.0102 (UniProt No. Q6474). The sequence identity between Ara h 11 and the two Ara h 10 isoforms is only $30 \%$. According to www.allergen.org, both Ara h 10 and Ara h 11 were recognized by IgE of 7 peanutallergic patients as determined by Blot/CAP performed with a purified natural oleosin fraction obtained from peanut oil bodies. An 18-kDa peanut oleosin (UniProt No. Q9AXI1) shows a sequence identity of $57 \%$ to Ara h 10.0101 and $42 \%$ to Ara h 11.

Pons et al. showed specific IgE-binding to this $18-\mathrm{kDa}$ oleosin isolated from purified peanut oil bodies in 3 of 14 sera of patients allergic to peanut [95]. IgE reactivity of the $18 \mathrm{kDa}$ oleosin increased when roasting peanuts. The oleosin monomer displayed only weak IgE-binding but strong IgE-binding to its oligomers of 34,50 , and $60 \mathrm{kDa}$ was observed. The authors also point to a possible cross-reactivity between peanut and soy, as the two sera with peanut oleosin-specific IgE also reacted with soy oleosins. The cross-reactivity of peanut and soy oleosins is based on their high sequence identity ranging from 50 to $79 \%$.

The most recently reported IgE-binding peanut oleosin, oleosin 3 (UniProt No. Q647G3), is a 16.8-kDa molecule and shows only up to $41 \%$ identity to the other three oleosins [99]. An oleosine 3 peptide derived from $\alpha$-chemotryptic hydrolysate of total peanut proteins appears to be an IgE epitope crossreacting with buckwheat. The peptide identified as SDQTRTG $\mathrm{Y}$ is identical to amino acids 2-9 in the N-terminal hydrophilic domain of oleosin 3 and was found to bind $\operatorname{IgE}$ of all 8 tested peanut-allergic sera. The peptide inhibited IgE-binding to the PBS-soluble fraction of buckwheat in a range of 10-50\% using sera of 7 peanut-allergic patients.
Oleosins have also been identified as allergens in two other seeds, namely sesame [101] and hazelnut [102]. Ara h 10 isoforms show a higher sequence identity to the hazelnut oleosin Cor a $12(56 \%)$ and the sesame oleosin Ses i 4 (42\%), while Ara h 11 shows higher sequence identity to Cor a $13(69 \%)$ and Ses i 5 (75\%). Nevertheless, the clinical relevance and IgE cross-reactivity of these allergens are unknown and requires more research.

\section{The Peanut Defensins Ara h 12 and Ara h 13}

Plant defensins are small, highly stable, cysteine-rich peptides that are a part of the innate immune system and that have antifungal, antibacterial, protease inhibitory, or insect amylase inhibitory activity [103]. Ara h 12 and Ara h 13 are peanut defensins that were isolated by methanol/chloroform extraction from ground peanuts [104]. IgE reactivity was shown for a small number of sera with severe peanut allergy. As peanut defensins have only low sequence identity with the allergenic defensins from soybean (Gly m 2) and mugwort pollen (Art v 1), crossreactivity is not to be expected.

\section{Cross-Reactivity of Peanut Allergens with Lupin Allergens}

The interest to exploit alternative vegetable protein sources to soy has led to an increasing use of sweet lupin seed flour in bakery, confectionary, snack, and pastry products as an additive to wheat flour or as a substitute for soy flour. Lupin allergy seems to appear in patients with an existing peanut allergy but can also manifest in isolation [105, 106]. The majority of lupin seed proteins are comprised of $\alpha$-conglutins (legumin-like) and $\beta$-conglutins (vicilin-like), and to a lesser extent $\gamma$-conglutins (vicilin-like) and $\delta$-conglutins ( $2 \mathrm{~S}$ albumins). Sera from six patients with a positive double-blind, placebo-controlled food challenge to lupin protein-containing food preparations and a coexisting peanut allergy were used to analyze the crossreactivity of legume seed storage proteins [107]. While all sera reacted with the legumin-like $\alpha$-conglutin fraction, IgE from sera of five of the six study individuals bound to the vicilin-like $\beta$-conglutins. In an indirect ELISA, peanut and almond protein extracts were able to inhibit IgE-binding to the lupin protein extract. As individual lupin conglutin fractions were not coated to the plates, the extent of inhibition by Ara h 1 or Ara $\mathrm{h} 3$ was not determined. In a follow-up study again using six lupin allergic patients' sera, the inhibitory capacity of Ara $\mathrm{h} 1$, Ara h 2, and Ara h 3 on IgE binding to lupin conglutins was determined [108]. While Ara h 1 most potently cross-reacted with $\beta$-conglutin and Ara h 2 with $\delta$-conglutin, Ara h 3 only displayed inhibition of IgE binding to $\alpha$-conglutin at highest concentrations. It is worth to note that the $2 \mathrm{~S}$ albumin Ara h 2 
showed the strongest inhibition of the legumin-like $\alpha$-conglutin indicating a cross-reactivity between unrelated allergens, as has been described by Bublin and colleagues for peanut [11•].

A $\beta$-conglutin from L. angustifolius is included as the allergen Lup an 1 in the official allergen nomenclature database [109]. Another lupin vicilin-like protein with IgE-binding capacity from $L$. albus named Lup-1 showed around $40 \%$ sequence identity to related allergens from peanut (Ara h 1), pea (Pis s 1), and lentil (Len c 1) [110]. A recent study recruited 12 peanut-allergic children to identify the lupin allergens responsible for cross-reactivity with peanut [111]. The results suggested the $\beta$-conglutin Lup an 1 as the major cross-reactive lupin allergen having been recognized by cutaneous IgE in $7 / 12$ patients. In skin prick tests, $4 / 12$ patients tested positive to $\gamma$-conglutin, $5 / 12$ to $\alpha$-conglutin, and $3 / 12$ to $\delta$-conglutin.

In skin prick tests performed on ten well-characterized peanut-allergic patients, seeds from eight different legume species produced positive results [112]. In a Western blot, sera from a subgroup of these patients showed $\operatorname{IgE}$ binding to vicilins from soybean, pea, and lupine seeds. Ballabio and colleagues studied the cross-reactivity of peanut allergens and proteins from lupin, lentil, pea, kidney bean, and soybean in 12 peanut-allergic subjects [113]. Using a combination of immunoblotting, N-terminal sequencing, and skin prick testing, the basic subunits of the 11S globulins were identified as the most cross-reactive polypeptides in this patient cohort.

\section{Conclusions}

Peanut allergens such as the Bet v 1-related Ara $\mathrm{h} 8$, the peanut profilin Ara h 5, and the nsLTP Ara h 9 are types of allergens that are considered as panallergens. Such allergens are responsible for allergic cross-reactivities across a wide variety of unrelated plants and are often associated with birch and grass pollinosis or involved in the so-called nsLTP-syndrome. On the other hand, the vicilin Ara h 1, the $2 \mathrm{~S}$ albumins Ara $\mathrm{h} 2$ and Ara h 6, and the legumin Ara h 3 represent major constituents of the peanut that frequently bind IgE. Co-sensitization to these allergens seems to be predictive of more severe reactions. Among these, Ara h 2 has been identified as an important predictor of clinical reactivity to peanut. Together with Ara $h$ 6 , Ara h 2 accounted for the majority of the effector activity in peanut extracts, and the two allergens were the major elicitors of anaphylaxis in peanut-allergic mice. Thus, Zhuang and Dreskin suggested a redefiniton of the major peanut allergens with only Ara h 2 and Ara h 6 to be termed major allergens [114•].

In our recent study [11•], we found that the members of two unrelated protein families, the $2 \mathrm{~S}$ albumins and the cupins, are highly cross-reactive in peanut. This is due to the presence of highly similar sequence stretches present on surface-exposed loops. IgE cross-reactive between Ara h 2, Ara h 1, and Ara h
3 comprises the major fraction of IgE-specific for these allergens. It also has the highest affinity to Ara h 2. Likewise, other researchers observed cross-reactivates between unrelated allergens, indicting that simple comparison of amino acid sequences may be insufficient to predict cross-reactivity. The presence of IgE cross-reactivity between peanut allergens and allergens from other legumes and tree nuts has been demonstrated in some studies, but the identification of the involved individual allergens is still limited. Such studies are needed to answer the question whether allergic reactions to legumes and tree nuts in peanut-allergic individuals are a result of a primary allergy to peanut or cross-reactivity.

Acknowledgment Heimo Breiteneder wishes to acknowledge the support of the Austrian Science Fund's doctoral program W 1248-B13.

\section{Compliance with Ethics Guidelines}

Conflict of Interest Merima Bublin declares that she has no conflict of interest.

Heimo Breiteneder has received support from the Austrian Science Fund grants SFB 4608 and doctoral program W 1248-B13.

Human and Animal Rights and Informed Consent This article does not contain any studies with human or animal subjects performed by any of the authors.

Open Access This article is distributed under the terms of the Creative Commons Attribution License which permits any use, distribution, and reproduction in any medium, provided the original author(s) and the source are credited.

\section{References}

Papers of particular interest, published recently, have been highlighted as:

- Of importance

1. Sebei K, Gnouma A, Herchi W, Sakouhi F, Boukhchina S. Lipids, proteins, phenolic composition, antioxidant and antibacterial activities of seeds of peanuts (Arachis hypogaea 1) cultivated in Tunisia. Biol Res. 2013;46(3):257-63.

2. Koppelman SJ, Vlooswijk RA, Knippels LM, Hessing M, Knol EF, van Reijsen FC, et al. Quantification of major peanut allergens Ara $\mathrm{h} 1$ and Ara h 2 in the peanut varieties Runner, Spanish, Virginia, and Valencia, bred in different parts of the world. Allergy. 2001;56(2):132-7.

3. Hebling CM, Ross MM, Callahan JH, McFarland MA. Sizeselective fractionation and visual mapping of allergen protein chemistry in Arachis hypogaea. J Proteome Res. 2012;11(11): 5384-95.

4. Gribaldo S, Brochier-Armanet C. The origin and evolution of Archaea: a state of the art. Philos Trans R Soc Lond B Biol Sci. 2006;361(1470): 1007-22.

5. Brochier-Armanet C, Forterre P, Gribaldo S. Phylogeny and evolution of the Archaea: one hundred genomes later. Curr Opin Microbiol. 2011;14(3):274-81. 
6. Dunwell JM, Khuri S, Gane PJ. Microbial relatives of the seed storage proteins of higher plants: conservation of structure and diversification of function during evolution of the cupin superfamily. Microbiol Mol Biol Rev. 2000;64(1):153-79.

7. Breiteneder $\mathrm{H}$, Radauer $\mathrm{C}$. A classification of plant food allergens. J Allergy Clin Immunol. 2004;113(5):821-30.

8. Sako Y, Nomura N, Uchida A, Ishida Y, Morii H, Koga Y, et al. Aeropyrum pernix gen. nov., sp. nov., a novel aerobic hyperthermophilic archaeon growing at temperatures up to 100 degrees $\mathrm{C}$. Int J Syst Bacteriol. 1996;46(4):1070-7.

9. Radauer C, Lackner P, Breiteneder H. The Bet $\mathrm{v} 1$ fold: an ancient, versatile scaffold for binding of large, hydrophobic ligands. BMC Evol Biol. 2008;8:286.

10. Edstam MM, Viitanen L, Salminen TA, Edqvist J. Evolutionary history of the non-specific lipid transfer proteins. Mol Plant. 2011;4(6):947-64. This study of the evolutionary history indicated that the nsLTP family has evolved after plants conquered land and provided a novel perspective in the search for the biological function of this enigmatic family.

11. Bublin M, Kostadinova M, Radauer C, Hafner C, Szepfalusi Z, Varga EM, et al. IgE cross-reactivity between the major peanut allergen Ara h 2 and the nonhomologous allergens Ara h 1 and Ara h 3. J Allergy Clin Immunol. 2013;132(1):118-24. This paper describes for the first time the IgE cross-reactivity between unrelated peanut allergens indicating that Ara $h 2$ might act as the primary sensitizing molecule in peanut-allergic individuals.

12. Lin J, Bruni FM, Fu ZY, Maloney J, Bardina L, Boner AL, et al. A bioinformatics approach to identify patients with symptomatic peanut allergy using peptide microarray immunoassay. J Allergy Clin Immunol. 2012;129(5):1321-U202.

13. Nicolaou N, Murray C, Belgrave D, Poorafshar M, Simpson A, Custovic A. Quantification of specific IgE to whole peanut extract and peanut components in prediction of peanut allergy. J Allergy Clin Immunol. 2011;127(3):684-5.

14. Nicolaou N, Poorafshar M, Murray C, Simpson A, Winell H, Kerry G, et al. Allergy or tolerance in children sensitized to peanut: prevalence and differentiation using component-resolved diagnostics. J Allergy Clin Immunol. 2010;125(1):191-7.

15. Shreffler WG, Beyer K, Chu TH, Burks AW, Sampson HA. Microarray immunoassay: association of clinical history, in vitro IgE function, and heterogeneity of allergenic peanut epitopes. J Allergy Clin Immunol. 2004;113(4):776-82.

16. Astier C, Morisset M, Roitel O, Codreanu F, Jacquenet S, Franck $\mathrm{P}$, et al. Predictive value of skin prick tests using recombinant allergens for diagnosis of peanut allergy. J Allergy Clin Immunol. 2006;118(1):250-6.

17. Asarnoj A, Moverare R, Ostblom E, Poorafshar M, Lilja G, Hedlin G, et al. IgE to peanut allergen components: relation to peanut symptoms and pollen sensitization in 8-year-olds. Allergy. 2010;65(9):1189-95.

18. Flinterman AE, Knol EF, Lencer DA, Bardina L, den Hartog Jager $\mathrm{CF}$, Lin J, et al. Peanut epitopes for IgE and IgG4 in peanutsensitized children in relation to severity of peanut allergy. $\mathrm{J}$ Allergy Clin Immunol. 2008;121(3):737-43.

19. Peeters KA, Koppelman SJ, van Hoffen E, van der Tas CW, den Hartog Jager CF, Penninks AH, et al. Does skin prick test reactivity to purified allergens correlate with clinical severity of peanut allergy? Clin Exp Allergy. 2007;37(1):108-15.

20. Peeters KA, Koppelman SJ, Penninks AH, Lebens A, BruijnzeelKoomen CA, Hefle SL, et al. Clinical relevance of sensitization to lupine in peanut-sensitized adults. Allergy. 2009;64(4):549-55.

21. Klemans RJ, Knol EF, Michelsen-Huisman A, Pasmans SG, de Kruijf-Broekman W, Bruijnzeel-Koomen CA, et al. Components in soy allergy diagnostics: Gly $\mathrm{m} 2 \mathrm{~S}$ albumin has the best diagnostic value in adults. Allergy. 2013;68(11):1396-402. This paper first described the diagnostic value of IgE specific for $2 S$ albumin
Gly $m 8$ having the accuracy equal to currently used SPT or $\operatorname{sgE}$ to soy extract.

22. Sicherer SH, Munoz-Furlong A, Sampson HA. Prevalence of peanut and tree nut allergy in the United States determined by means of a random digit dial telephone survey: a 5-year follow-up study. J Allergy Clin Immunol. 2003;112(6):1203-7.

23. Clark AT, Ewan PW. The development and progression of allergy to multiple nuts at different ages. Pediatr Allergy Immunol. 2005;16(6):507-11.

24. Maloney JM, Rudengren M, Ahlstedt S, Bock SA, Sampson HA. The use of serum-specific IgE measurements for the diagnosis of peanut, tree nut, and seed allergy. J Allergy Clin Immunol. 2008;122(1):145-51.

25. Glaspole IN, de Leon MP, Prickett SR, O'Hehir RE, Rolland JM. Clinical allergy to hazelnut and peanut: identification of $\mathrm{T}$ cell cross-reactive allergens. Int Arch Allergy Immunol. 2011;155(4): 345-54.

26. de Leon MP, Glaspole IN, Drew AC, Rolland JM, O'Hehir RE, Suphioglu C. Immunological analysis of allergenic cross-reactivity between peanut and tree nuts. Clin Exp Allergy. 2003;33(9):1273-80.

27. de Leon MP, Drew AC, Glaspole IN, Suphioglu C, Rolland JM, O'Hehir RE. Functional analysis of cross-reactive immunoglobulin E antibodies: peanut-specific immunoglobulin E sensitizes basophils to tree nut allergens. Clin Exp Allergy. 2005;35(8): 1056-64.

28. Kulis M, Pons L, Burks AW. In vivo and T cell cross-reactivity between walnut, cashew and peanut. Int Arch Allergy Immunol. 2009;148(2):109-17.

29. Chassaigne H, Tregoat V, Norgaard JV, Maleki SJ, van Hengel AJ. Resolution and identification of major peanut allergens using a combination of fluorescence two-dimensional differential gel electrophoresis, Western blotting and Q-TOF mass spectrometry. J Proteomics. 2009;72(3):511-26.

30. Hebling CM, McFarland MA, Callahan JH, Ross MM. Global proteomic screening of protein allergens and advanced glycation endproducts in thermally processed peanuts. J Agric Food Chem. 2013;61(24):5638-48.

31. Burks AW, Cockrell G, Stanley JS, Helm RM, Bannon GA. Recombinant peanut allergen Ara h I expression and IgE binding in patients with peanut hypersensitivity. J Clin Invest. 1995;96(4): 1715-21.

32. Shewry PR, Napier JA, Tatham AS. Seed storage proteins: structures and biosynthesis. Plant Cell. 1995;7(7):945-56.

33. Cabanos C, Urabe H, Tandang-Silvas MR, Utsumi S, Mikami B, Maruyama N. Crystal structure of the major peanut allergen Ara $h$ 1. Mol Immunol. 2011;49(1-2):115-23.

34. Chruszcz M, Maleki SJ, Majorek KA, Demas M, Bublin M, Solberg $\mathrm{R}$, et al. Structural and immunologic characterization of Ara h 1, a major peanut allergen. J Biol Chem. 2011;286(45):39318-27. This article includes a comprehensive structural, immunological analysis of Ara $h 1$ analysis of Ara $h 1$ structure and elucidates the molecular basis of cross-reactivity between allergenic vicilin.

35. Maruyama N, Katsube T, Wada Y, Oh MH, Barba De La Rosa AP, Okuda E, et al. The roles of the N-linked glycans and extension regions of soybean beta-conglycinin in folding, assembly and structural features. Eur J Biochem. 1998;258(2):854-62.

36. Sanchez-Monge R, Lopez-Torrejon G, Pascual CY, Varela J, Martin-Esteban M, Salcedo G. Vicilin and convicilin are potential major allergens from pea. Clin Exp Allergy. 2004;34(11):1747-53.

37. Wang F, Robotham JM, Teuber SS, Tawde P, Sathe SK, Roux KH. Ana o 1, a cashew (Anacardium occidental) allergen of the vicilin seed storage protein family. J Allergy Clin Immunol. 2002;110(1): 160-6.

38. Teuber SS, Jarvis KC, Dandekar AM, Peterson WR, Ansari AA. Identification and cloning of a complementary DNA encoding a vicilin-like proprotein, jug $\mathrm{r} 2$, from english walnut kernel (Juglans 
regia), a major food allergen. $\mathrm{J}$ Allergy Clin Immunol. 1999;104(6):1311-20.

39. Lopez-Torrejon G, Salcedo G, Martin-Esteban M, Diaz-Perales A, Pascual CY, Sanchez-Monge R. Len c 1, a major allergen and vicilin from lentil seeds: protein isolation and cDNA cloning. J Allergy Clin Immunol. 2003;112(6):1208-15.

40. Beyer K, Bardina L, Grishina G, Sampson HA. Identification of sesame seed allergens by 2-dimensional proteomics and Edman sequencing: seed storage proteins as common food allergens. J Allergy Clin Immunol. 2002;110(1):154-9.

41. Lauer I, Foetisch K, Kolarich D, Ballmer-Weber BK, Conti A, Altmann F, et al. Hazelnut (Corylus avellana) vicilin Cor a 11: molecular characterization of a glycoprotein and its allergenic activity. Biochem J. 2004;383(Pt 2):327-34.

42. Maruyama N, Adachi M, Takahashi K, Yagasaki K, Kohno M, Takenaka Y, et al. Crystal structures of recombinant and native soybean beta-conglycinin beta homotrimers. Eur J Biochem. 2001;268(12):3595-604.

43. Barre A, Sordet C, Culerrier R, Rance F, Didier A, Rouge P. Vicilin allergens of peanut and tree nuts (walnut, hazelnut and cashew nut) share structurally related IgE-binding epitopes. Mol Immunol. 2008;45(5):1231-40.

44. Kroghsbo S, Bogh KL, Rigby NM, Mills EN, Rogers A, Madsen CB. Sensitization with 7S globulins from peanut, hazelnut, soy or pea induces IgE with different biological activities which are modified by soy tolerance. Int Arch Allergy Immunol. 2011;155(3):212-24. This article addresses the determination of the allergenic potential of related $7 S$ globulins in a Brown Norway rat model. The authors showed that natural peanut Ara $\mathrm{h} 1$ induced IgE of higher avidity than hazelnut Cor a 11, pea Pis s, and soy Gly $m 5$.

45. Rosenfeld L, Shreffler W, Bardina L, Niggemann B, Wahn U, Sampson HA, et al. Walnut allergy in peanut-allergic patients: significance of sequential epitopes of walnut homologous to linear epitopes of Ara h 1, 2 and 3 in relation to clinical reactivity. Int Arch Allergy Immunol. 2012;157(3):238-45.

46. Rabjohn P, Helm EM, Stanley JS, West CM, Sampson HA, Burks AW, et al. Molecular cloning and epitope analysis of the peanut allergen Ara h 3. J Clin Invest. 1999;103(4):535-42.

47. Jin T, Guo F, Chen YW, Howard A, Zhang YZ. Crystal structure of Ara h 3, a major allergen in peanut. Mol Immunol. 2009;46(89):1796-804.

48. Beardslee TA, Zeece MG, Sarath G, Markwell JP. Soybean glycinin G1 acidic chain shares IgE epitopes with peanut allergen Ara h 3. Int Arch Allergy Immunol. 2000;123(4):299-307.

49. Wang F, Robotham JM, Teuber SS, Sathe SK, Roux KH. Ana o 2, a major cashew (Anacardium occidentale L.) nut allergen of the legumin family. Int Arch Allergy Immunol. 2003;132(1):27-39.

50. Wallowitz M, Peterson WR, Uratsu S, Comstock SS, Dandekar AM, Teuber SS. Jug $\mathrm{r} 4$, a legumin group food allergen from walnut (Juglans regia C $v$. Chandler). J Agric Food Chem. 2006;54(21):8369-75.

51. Beyer K, Grishina G, Bardina L, Sampson HA. Identification of 2 new sesame seed allergens: Ses i 6 and Ses i 7. J Allergy Clin Immunol. 2007;119(6):1554-6.

52. Beyer K, Grishina G, Bardina L, Grishin A, Sampson HA. Identification of an $11 \mathrm{~S}$ globulin as a major hazelnut food allergen in hazelnut-induced systemic reactions. J Allergy Clin Immunol. 2002;110(3):517-23.

53. Adachi M, Takenaka Y, Gidamis AB, Mikami B, Utsumi S. Crystal structure of soybean proglycinin $\mathrm{A} 1 \mathrm{aB} 1 \mathrm{~b}$ homotrimer. J Mol Biol. 2001;305(2):291-305.

54. Adachi M, Kanamori J, Masuda T, Yagasaki K, Kitamura K, Mikami B, et al. Crystal structure of soybean $11 \mathrm{~S}$ globulin: glycinin A3B4 homohexamer. Proc Natl Acad Sci U S A. 2003;100(12):7395-400.
55. Tandang-Silvas MR, Fukuda T, Fukuda C, Prak K, Cabanos C, Kimura A, et al. Conservation and divergence on plant seed 11S globulins based on crystal structures. Biochim Biophys Acta. 2010;1804(7):1432-42.

56. Jin T, Albillos SM, Guo F, Howard A, Fu TJ, Kothary MH, et al. Crystal structure of prunin-1, a major component of the almond (Prunus dulcis) allergen amandin. J Agric Food Chem. 2009;57(18):8643-51.

57. Barre A, Jacquet G, Sordet C, Culerrier R, Rouge P. Homology modelling and conformational analysis of IgE-binding epitopes of Ara h 3 and other legumin allergens with a cupin fold from tree nuts. Mol Immunol. 2007;44(12):3243-55.

58. Vereda A, Sirvent S, Villalba M, Rodriguez R, Cuesta-Herranz J, Palomares O. Improvement of mustard (Sinapis alba) allergy diagnosis and management by linking clinical features and componentresolved approaches. J Allergy Clin Immunol. 2011;127(5):1304-7. This work contributes to the diagnosis and management of mustard allergy by correlating clinical symptoms of patients with their sensitization profiles to specific mustard allergens.

59. Sirvent S, Akotenou M, Cuesta-Herranz J, Vereda A, Rodriguez $\mathrm{R}$, Villalba $\mathrm{M}$, et al. The $11 \mathrm{~S}$ globulin Sin a 2 from yellow mustard seeds shows IgE cross-reactivity with homologous counterparts from tree nuts and peanut. Clin Transl Allergy. 2012;2(1):23.

60. Radauer C, Bublin M, Wagner S, Mari A, Breiteneder H. Allergens are distributed into few protein families and possess a restricted number of biochemical functions. J Allergy Clin Immunol. 2008;121(4):847-52.

61. Shewry PR, Beaudoin F, Jenkins J, Griffiths-Jones S, Mills ENC. Plant protein families and their relationships to food allergy. Biochem Soc Trans. 2002;30:906-10.

62. Marsh J, Rigby N, Wellner K, Reese G, Knulst A, Akkerdaas J, et al. Purification and characterisation of a panel of peanut allergens suitable for use in allergy diagnosis. Mol Nutr Food Res. 2008;52 Suppl 2:S272-85.

63. Lehmann K, Schweimer K, Reese G, Randow S, Suhr M, Becker $\mathrm{WM}$, et al. Structure and stability of $2 \mathrm{~S}$ albumin-type peanut allergens: implications for the severity of peanut allergic reactions. Biochem J. 2006;395(3):463-72.

64. Mueller GA, Gosavi RA, Pomes A, Wunschmann S, Moon AF, London RE, et al. Ara h 2: crystal structure and $\operatorname{IgE}$ binding distinguish two subpopulations of peanut allergic patients by epitope diversity. Allergy. 2011;66(7):878-85.

65. Burks AW, Williams LW, Connaughton C, Cockrell G, O'Brien TJ, Helm RM. Identification and characterization of a second major peanut allergen, Ara h II, with use of the sera of patients with atopic dermatitis and positive peanut challenge. J Allergy Clin Immunol. 1992;90(6):962-9.

66. Chatel JM, Bernard H, Orson FM. Isolation and characterization of two complete Ara h 2 isoforms cDNA. Int Arch Allergy Immunol. 2003;131(1):14-8.

67. Hales BJ, Bosco A, Mills KL, Hazell LA, Loh R, Holt PG, et al. Isoforms of the major peanut allergen Ara $\mathrm{h}$ 2: IgE binding in children with peanut allergy. Int Arch Allergy Immunol. 2004;135(2):101-7.

68. Li J, Shefcheck K, Callahan J, Fenselau C. Primary sequence and site-selective hydroxylation of prolines in isoforms of a major peanut allergen protein Ara h 2. Protein Sci. 2010;19(1):174-82.

69. King N, Helm R, Stanley JS, Vieths S, Luttkopf D, Hatahet L, et al. Allergenic characteristics of a modified peanut allergen. Mol Nutr Food Res. 2005;49(10):963-71.

70. Albrecht M, Kuhne Y, Ballmer-Weber BK, Becker WM, Holzhauser T, Lauer I, et al. Relevance of IgE binding to short peptides for the allergenic activity of food allergens. J Allergy Clin Immunol. 2009;124(2):328-36.

71. Hazebrouck S, Guillon B, Drumare MF, Paty E, Wal JM, Bernard H. Trypsin resistance of the major peanut allergen Ara h 6 and 
allergenicity of the digestion products are abolished after selective disruption of disulfide bonds. Mol Nutr Food Res. 2012;56(4):548 57.

72. Porterfield HS, Murray KS, Schlichting DG, Chen X, Hansen KC, Duncan MW, et al. Effector activity of peanut allergens: a critical role for Ara h 2, Ara h 6, and their variants. Clin Exp Allergy. 2009;39(7):1099-108.

73. Chen XN, Wang Q, El-Mezayen R, Zhuang YH, Dreskin SC. Ara h 2 and Ara h 6 have similar allergenic activity and are substantially redundant. Int Arch Allergy Immunol. 2013;160(3):251-8.

74. Kulis M, Chen X, Lew J, Wang Q, Patel OP, Zhuang Y, et al. The $2 \mathrm{~S}$ albumin allergens of Arachis hypogaea, Ara h 2 and Ara h 6, are the major elicitors of anaphylaxis and can effectively desensitize peanut-allergic mice. Clin Exp Allergy. 2012;42(2):326-36. This study provides the novel finding that using Ara $\mathrm{h} 2$ and Ara $h$ 6 alone produced an equivalent level of desensitization to using an extract containing all major peanut allergens in immunotherapy of peanut-allergic mice.

75. de Leon MP, Drew AC, Glaspole IN, Suphioglu C, O'Hehir RE, Rolland JM. IgE cross-reactivity between the major peanut allergen Ara h 2 and tree nut allergens. Mol Immunol. 2007;44(4):463-71.

76. Maleki SJ, Teuber SS, Cheng H, Chen D, Comstock SS, Ruan S, et al. Computationally predicted $\operatorname{IgE}$ epitopes of walnut allergens contribute to cross-reactivity with peanuts. Allergy. 2011;66(12): $1522-9$.

77. Kleber-Janke T, Crameri R, Appenzeller U, Schlaak M, Becker WM. Selective cloning of peanut allergens, including profilin and $2 \mathrm{~S}$ albumins, by phage display technology. Int Arch Allergy Immunol. 1999;119(4):265-74.

78. Schmidt H, Krause S, Gelhaus C, Petersen A, Janssen O, Becker WM. Detection and structural characterization of natural Ara h 7, the third peanut allergen of the $2 \mathrm{~S}$ albumin family. J Proteome Res. 2010;9(7):3701-9.

79. Codreanu F, Collignon O, Roitel O, Thouvenot B, Sauvage C, Vilain AC, et al. A novel immunoassay using recombinant allergens simplifies peanut allergy diagnosis. Int Arch Allergy Immunol. 2011;154(3):216-26.

80. Yeats TH, Rose JK. The biochemistry and biology of extracellular plant lipid-transfer proteins (LTPs). Protein Sci. 2008;17(2):191-8.

81. Krause S, Reese G, Randow S, Zennaro D, Quaratino D, Palazzo $\mathrm{P}$, et al. Lipid transfer protein (Ara h 9) as a new peanut allergen relevant for a Mediterranean allergic population. J Allergy Clin Immunol. 2009;124(4):771-8.

82. Lauer I, Dueringer N, Pokoj S, Rehm S, Zoccatelli G, Reese G, et al. The non-specific lipid transfer protein, Ara $\mathrm{h}$ 9, is an important allergen in peanut. Clin Exp Allergy. 2009;39(9):1427-37.

83. Vereda A, van Hage M, Ahlstedt S, Ibanez MD, Cuesta-Herranz J, van Odijk J, et al. Peanut allergy: clinical and immunologic differences among patients from 3 different geographic regions. J Allergy Clin Immunol. 2011;127(3):603-7. This study shows that peanut-allergic patients recognize different allergens and display different clinical symptoms in different areas of the world, possibly due to different pollen exposures and culinary traditions.

84. Javaloyes G, Goikoetxea MJ, Garcia Nunez I, Aranda A, Sanz ML, Blanca M, et al. Pru p 3 acts as a strong sensitizer for peanut allergy in Spain. J Allergy Clin Immunol. 2012;130(6):1432-4.

85. Cabanos C, Tandang-Silvas MR, Odijk V, Brostedt P, Tanaka A, Utsumi $\mathrm{S}$, et al. Expression, purification, cross-reactivity and homology modeling of peanut profilin. Protein Expr Purif. 2010;73(1):36-45.

86. Kleber-Janke T, Crameri R, Scheurer S, Vieths S, Becker WM. Patient-tailored cloning of allergens by phage display: peanut (Arachis hypogaea) profilin, a food allergen derived from a rare mRNA. J Chromatogr B Biomed Sci Appl. 2001;756(1-2):295-305.
87. Wang Y, Fu TJ, Howard A, Kothary MH, McHugh TH, Zhang Y. Crystal structure of peanut (Arachis hypogaea) allergen Ara h 5. J Agric Food Chem. 2013;61(7):1573-8.

88. Mittag D, Akkerdaas J, Ballmer-Weber BK, Vogel L, Wensing M, Becker WM, et al. Ara h 8, a Bet v 1-homologous allergen from peanut, is a major allergen in patients with combined birch pollen and peanut allergy. J Allergy Clin Immunol. 2004;114(6):1410-7.

89. Guarneri F, Guarneri C, Benvenga S. Identification of potentially cross-reactive peanut-lupine proteins by computer-assisted search for amino acid sequence homology. Int Arch Allergy Immunol. 2005;138(4):273-7.

90. Mittag D, Batori V, Neudecker P, Wiche R, Friis EP, Ballmer-Weber BK, et al. A novel approach for investigation of specific and cross-reactive IgE epitopes on Bet $\mathrm{v} 1$ and homologous food allergens in individual patients. Mol Immunol. 2006;43(3):268-78.

91. Riecken S, Lindner B, Petersen A, Jappe U, Becker WM. Purification and characterization of natural Ara $\mathrm{h} 8$, the Bet $\mathrm{v} 1$ homologous allergen from peanut, provides a novel isoform. Biol Chem. 2008;389(4):415-23.

92. Hurlburt BK, Offermann LR, McBride JK, Majorek KA, Maleki SJ, Chruszcz M. Structure and function of the peanut panallergen Ara h 8. J Biol Chem. 2013;288(52):36890-901. Hurlburt and colleagues have solved the structure of Ara $\mathrm{h} 8$ and demonstrated that several biological relevant compounds such as apiginin, quercetin, and daidzein can bind to the protein suggesting that Ara h 8 might serve as a delivery vehicle for flavonoids.

93. Seutter von Loetzen C, Hoffmann T, Hartl MJ, Schweimer K, Schwab W, Rosch P et al. The secret of the major birch pollen allergen Bet $\mathrm{v} 1$ - identification of the physiological ligand. Biochem J. 2014;457(3):379-90.

94. Petersen A, Rennert S, Kull S, Becker WM, Notbohm H, Goldmann $\mathrm{T}$ et al. Roasting and lipid binding provide allergenic and proteolytic stability to the peanut allergen Ara h 8. Biol Chem. 2014;395(2):239-50.

95. Pons L, Chery C, Romano A, Namour F, Artesani MC, Gueant JL. The $18 \mathrm{kDa}$ peanut oleosin is a candidate allergen for IgE-mediated reactions to peanuts. Allergy. 2002;57 Suppl 72:88-93.

96. Huang AHC. Oil bodies and oleosins in seeds. Annu Rev Plant Physiol Plant Mol Biol. 1992;43:177-200.

97. Hsieh K, Huang AHC. Endoplasmic reticulum, oleosins, and oils in seeds and tapetum cells. Plant Physiol. 2004;136(3):3427-34.

98. Parthibane V, Rajakumari S, Venkateshwari V, Iyappan R, Rajasekharan R. Oleosin is bifunctional enzyme that has both monoacylglycerol acyltransferase and phospholipase activities. J Biol Chem. 2012;287(3):1946-54.

99. Kobayashi S, Katsuyama S, Wagatsuma T, Okada S, Tanabe S. Identification of a new IgE-binding epitope of peanut oleosin that cross-reacts with buckwheat. Biosci Biotechnol Biochem. 2012;76(6):1182-8.

100. Pons L, Chery C, Mrabet N, Schohn H, Lapicque F, Gueant JL. Purification and cloning of two high molecular mass isoforms of peanut seed oleosin encoded by cDNAs of equal sizes. Plant Physiol Biochem. 2005;43(7):659-68.

101. Leduc V, Moneret-Vautrin DA, Tzen JT, Morisset M, Guerin L, Kanny G. Identification of oleosins as major allergens in sesame seed allergic patients. Allergy. 2006;61(3):349-56.

102. Akkerdaas JH, Schocker F, Vieths S, Versteeg S, Zuidmeer L, Hefle SL, et al. Cloning of oleosin, a putative new hazelnut allergen, using a hazelnut cDNA library. Mol Nutr Food Res. 2006;50(1):18-23.

103. Stotz HU, Thomson JG, Wang Y. Plant defensins: defense, development and application. Plant Signal Behav. 2009;4(11):1010-2.

104. Petersen A, Rennert S, Bottger M, Krause S, Gutsmann T, Lindner B, et al. Defensin: a novel allergen in peanuts. Allergy. 2012;67:374. 
105. Sanz ML, de Las Marinas MD, Fernandez J, Gamboa PM. Lupin allergy: a hidden killer in the home. Clin Exp Allergy. 2010;40(10):1461-6.

106. Campbell CP, Yates DH. Lupin allergy: a hidden killer at home, a menace at work; occupational disease due to lupin allergy. Clin Exp Allergy. 2010;40(10):1467-72.

107. Holden L, Sletten GB, Lindvik H, Faeste CK, Dooper MM. Characterization of IgE binding to lupin, peanut and almond with sera from lupin-allergic patients. Int Arch Allergy Immunol. 2008;146(4):267-76.

108. Dooper MM, Plassen C, Holden L, Lindvik H, Faeste CK. Immunoglobulin $\mathrm{E}$ cross-reactivity between lupine conglutins and peanut allergens in serum of lupine-allergic individuals. $\mathrm{J}$ Investig Allergol Clin Immunol. 2009;19(4):283-91.

109. Goggin DE, Mir G, Smith WB, Stuckey M, Smith PM. Proteomic analysis of lupin seed proteins to identify conglutin Beta as an allergen, Lup an 1. J Agric Food Chem. 2008;56(15):6370-7.

110. Guillamon E, Rodriguez J, Burbano C, Muzquiz M, Pedrosa MM, Cabanillas B, et al. Characterization of lupin major allergens (Lupinus albus L.). Mol Nutr Food Res. 2010;54(11):1668-76.

111. Ballabio C, Penas E, Uberti F, Fiocchi A, Duranti M, Magni C, et al. Characterization of the sensitization profile to lupin in peanut-allergic children and assessment of cross-reactivity risk. Pediatr Allergy Immunol. 2013;24(3):270-5.
112. Jensen LB, Pedersen MH, Skov PS, Poulsen LK, Bindslev-Jensen $\mathrm{C}$, Andersen SB, et al. Peanut cross-reacting allergens in seeds and sprouts of a range of legumes. Clin Exp Allergy. 2008;38(12): 1969-77.

113. Ballabio C, Magni C, Restani P, Mottini M, Fiocchi A, Tedeschi $\mathrm{G}$, et al. IgE-mediated cross-reactivity among leguminous seed proteins in peanut allergic children. Plant Foods Hum Nutr. 2010;65(4):396-402.

114. Zhuang YH, Dreskin SC. Redefining the major peanut allergens. Immunol Res. 2013;55(1-3):125-34. This review summarizes the recent studies on Ara $h 2$ and Ara $h 6$ and concludes that these proteins represent the only major allergens of peanut.

115. Pasquato N, Berni R, Folli C, Folloni S, Cianci M, Pantano S, et al. Crystal structure of peach Pru p 3, the prototypic member of the family of plant non-specific lipid transfer protein pan-allergens. $\mathbf{J}$ Mol Biol. 2006;356(3):684-94.

116. Flinterman AE, van Hoffen E, den Hartog Jager CF, Koppelman S, Pasmans SG, Hoekstra MO, et al. Children with peanut allergy recognize predominantly Ara $\mathrm{h} 2$ and Ara h 6, which remains stable over time. Clin Exp Allergy. 2007;37(8):1221-8.

117. Finkina EI, Shramova EI, Tagaev AA, Ovchinnikova TV. A novel defensin from the lentil Lens culinaris seeds. Biochem Biophys Res Commun. 2008;371(4):860-5. 